\title{
Coagulation performance and floc characteristics of polytitanium tetrachloride and titanium tetrachloride compared with ferric chloride for coal mining wastewater treatment
}

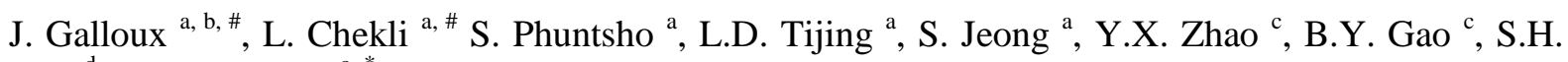
Park $^{\mathrm{d}}$ and H.K. Shon ${ }^{\mathrm{a}, *}$

${ }^{a}$ School of Civil and Environmental Engineering, University of Technology, Sydney, Post Box 129, Broadway, NSW 2007, Australia.

$10{ }^{\mathrm{b}}$ Energy and Environmental Engineering, National Institute of Applied Sciences of Lyon (INSA de 11 Lyon), 20 Avenue Albert Einstein, 69621 Villeurbanne, France

c Shandong Key Laboratory of Water Pollution Control and Resource Reuse, School of Environmental Science and Engineering, Shandong University, 27 Shanda South Road, Jinan, 250100, People's Republic of China.

d Advanced process and materials R\&BD Group, Korea Institute of Industrial Technology, 156 Gaetbeol-ro, Yeonsu-gu, Incheon, Republic of Korea.

*Corresponding author: Email: Hokyong.Shon-1@uts.edu.au; Phone: (+61) 0295142629

\#J.G. and L.C. equally contributed to this work

\section{Abstract:}

The production and discharge of large volumes of wastewater during coal mining activities are one of the major environmental issues in Australia. Therefore, it is crucial to develop and optimise effective treatment processes for the safe disposal of coal mining wastewater (CMWW). In this study, we investigated the performance of a recently developed polytitanium tetrachloride (PTC) coagulant and compared with the performance of titanium tetrachloride $\left(\mathrm{TiCl}_{4}\right)$ and the commonly used ferric chloride $\left(\mathrm{FeCl}_{3}\right)$ coagulant for the treatment of CMWW from one of the coal mining sites in Australia. The use of Ti-based coagulants is particularly attractive for the CMWW treatment due to the advantage of being able to recycle the sludge to produce functional titanium dioxide $\left(\mathrm{TiO}_{2}\right)$ photocatalyst; unlike the flocs formed using conventional coagulants, which need to be disposed in landfill sites. The results showed that both PTC and $\mathrm{TiCl}_{4}$ performed better than $\mathrm{FeCl}_{3}$ in terms of turbidity, $\mathrm{UV}_{254}$ and inorganic compounds (e.g. aluminium, copper or zinc) removal, however, PTC performed poorly in terms of dissolved organic carbon removal (i.e. less than 10\%). While charge neutralisation and bridging adsorption were the main coagulation mechanisms identified for $\mathrm{TiCl}_{4}$ treatment; sweep coagulation and bridging adsorption seemed to play a more important role for both PTC and $\mathrm{FeCl}_{3}$ treatments. The flocs formed by PTC coagulation achieved the largest floc size of around $900 \mu \mathrm{m}$ with the highest floc growth rate. Both Ti-based coagulants (i.e., PTC and $\mathrm{TiCl}_{4}$ ) 
37 showed higher strength factor than $\mathrm{FeCl}_{3}$, while $\mathrm{TiCl}_{4}$ coagulant yielded the flocs with the highest 38 recovery factor. This study indicates that Ti-based coagulants are effective and promising coagulants 39 for the treatment of CMWW.

40 Keywords: Coagulation; Coal mining wastewater; Polytitanium tetrachloride; Titanium tetrachloride. 


\section{Introduction}

The coal mining industry is one of the major industries in Australia, which contributes largely to its economy reaching a revenue of AUS\$ 39.8 billion in 2013 [1]. However, the activities associated with coal mining have significant environmental concerns, especially on the production and discharge of impaired mining water directly into the surrounding surface waters [2]. Coal mining wastewaters (CMWW) are generally saline, and contain very high concentration of suspended solids and variable concentrations of iron, aluminium and dissolved organic matter [3]. The most commonly employed treatment of CMWW is through a coagulation/flocculation process [4] although membrane processes such as microfiltration have also been adopted. Passive treatments such as the use of lagoons and wetlands are also quite common in Australia, however, ponding is restricted in the state of Queensland [5, 6].

Coagulation/flocculation is the most commonly employed treatment process for the removal of colloidal particles and organic matter in wastewater [7]. Both iron (Fe) and aluminium (Al) based salts have been widely used as coagulants since they have demonstrated high performance for the removal of a wide range of pollutants found in wastewaters [8]. As an example, in the Centennial Coal Mining site located in Fassifern, New South Wales, Australia, the currently-used method of CMWW treatment is through a coagulation/flocculation process using ferric chloride $\left(\mathrm{FeCl}_{3}\right)$ along with a cationic polymer. This site generates an average of 12-15 ML/d of CMWW. Though, there are successes in the use of both $\mathrm{Fe}$ and Al-salts as coagulants, however, its major drawback is the production of large quantities of coagulated sludge after the CMWW treatment process. Proper disposal of the sludge generated from coagulation/flocculation treatment presents a very costly and environmentally-problematic challenge of the CMWW treatment $[9,10]$. Thus, the development of new coagulants as well as advanced processes for sludge disposal and treatment has been sought out in the past years. Recently, Shon et al. [11] developed a novel titanium (Ti) based coagulant, namely titanium tetrachloride $\left(\mathrm{TiCl}_{4}\right)$, to circumvent the sludge disposal issue. The $\mathrm{TiCl}_{4}$ coagulant was found 
to have comparable performance as with those of the conventional $\mathrm{Al}$ and Fe-salts $[12,13]$, but the main novelty of the use of $\mathrm{TiCl}_{4}$ coagulant lies on the possibility of recycling the generated sludge via a simple calcination method to produce titanium dioxide $\left(\mathrm{TiO}_{2}\right)$ as a valuable by-product $[11,14,15]$. In fact, $\mathrm{TiO}_{2}$ is a widely used metal oxide finding applications in paints, solar cells, cosmetics, photocatalysts or electronic papers $[16,17]$.

The use of $\mathrm{TiCl}_{4}$ has opened doors for a more cost-effective coagulation to sludge disposal approach. However, it was observed that the optimum coagulation efficiency of $\mathrm{TiCl}_{4}$ occur at low $\mathrm{pH}$ values ranging from 3.0 to 5.0, mainly due to the release of large amounts of $\mathrm{H}^{+}$during the titanium hydrolysis $[11,13]$. Thus, some approaches were undertaken to address this issue so as to enable the Ti-based coagulant to be used at a wider $\mathrm{pH}$ range. A recent study resolved this issue by developing polytitanium salts which minimises the release of $\mathrm{H}^{+}$through prehydrolysis of titanium salt [18]. In their study [18], polytitanium tetrachloride (PTC) was synthesised by a slow alkaline titration method at different basicity values (i.e., at different $\mathrm{OH} / \mathrm{Ti}$ molar ratios in PTC solution) and used as a coagulant. Their results showed higher or comparable treatment performance of PTC compared to $\mathrm{TiCl}_{4}$ in terms of removal efficiency for turbidity and organic matter. Additionally, improved floc characteristics such as flocs size, growth rate and structure were also observed with the use of PTC. Earlier studies on inorganic polymeric coagulants such as polyaluminum sulphate or polyferric chloride [19-21] have suggested better performance compared to inorganic salts in terms of the removal of organic matter and various pollutants, and also for $\mathrm{pH}$ dependence.

Floc characteristics such as floc size, strength factor and recoverability are important factors for evaluating the performance of the coagulation process. For example, larger flocs settle faster than smaller flocs of similar density [22], which leads to not only higher removal efficiency but also faster floc settling time, thereby only requiring smaller sedimentation tanks. The ability of the floc to not only resist breakage but also its ability to recover after breakage will have a significant impact on water treatment processes and its capital and operation costs [23]. 
91 In the present study, we investigated and compared the coagulation performance of $\mathrm{PTC}$ and $\mathrm{TiCl}_{4}$ in

92 terms of their removal efficiency on turbidity, $\mathrm{UV}_{254}$, dissolved organic carbon (DOC), and inorganic

93 compounds from CMWW. Floc characteristics were studied by measuring the zeta potential, floc

94 sizes, as well as the floc recoverability. The results for the Ti-based coagulants were then compared

95 to those of the $\mathrm{Fe}$-salt coagulant (i.e. $\mathrm{FeCl}_{3}$ ), which is currently used to treat the $\mathrm{CMWW}$ from the

96 Centennial Coal Mining site located in Fassifern (NSW, Australia). A detailed flocs characterisation

97 was also undertaken to better understand the growth, breakage and re-growth of flocs formed by all

98 three coagulants.

992 Materials and Methods

$100 \quad 2.1 \quad$ Coagulants and coal mining wastewater

101 A stock solution of $\mathrm{TiCl}_{4}$ (>> 99\% purity, Sigma Aldrich, Australia) was prepared by slowly adding 102 (i.e. drop by drop) $46.4 \mathrm{~mL}$ of concentrated $\mathrm{TiCl}_{4}$ to frozen cubes of deionised water under continuous stirring to obtain the final concentration of $20 \% \mathrm{w} / \mathrm{w}$. The detailed method for the preparation of PTC solution can be found in Zhao et al. [18]. In brief, $63.3 \mathrm{~mL}$ of sodium hydroxide $(\mathrm{NaOH})$ was added to $200 \mathrm{~mL}$ of the prepared $\mathrm{TiCl}_{4}$ solution to obtain a final $\mathrm{OH} / \mathrm{Ti}$ ratio of 1.5 using a slow alkaline titration method. The stock solution of $\mathrm{FeCl}_{3}$ was prepared by simply dissolving $2 \mathrm{~g}$ of powder in 200 $\mathrm{mL}$ of deionised water to obtain the final concentration of $10 \mathrm{~g} / \mathrm{L}$.

CMWW was collected from the Centennial Coal Mining site at Newstan Colliery located near Fassifern in NSW, Australia. The detailed characteristics of the present CMWW are shown in Table 1.

\section{Table 1}

\section{$112 \quad 2.2 \quad$ Jar-test}

113 Jar-test experiments were carried out using a programmable jar-tester (PB-900TM, Phipps and Bird, 114 USA). Several preliminary tests were first carried out to determine the optimum coagulant dose. After 
115 optimisation, the predetermined (i.e. optimised) amount of coagulant was then added to $500 \mathrm{~mL}$ of

116 CMWW. Rapid mixing at $200 \mathrm{rpm}$ was first applied for 1.5 minutes followed by 20 minutes of slow

117 mixing at $40 \mathrm{rpm}$, and finally 20 minutes of quiescent settling. Water samples were then collected

118 from $2 \mathrm{~cm}$ below the surface for further analysis. Turbidity and floc zeta potential were directly 119 measured using 2100P turbidity meter (Hach, USA) and Zetasizer (Malvern Instruments, UK), 120 respectively. Water samples were pre-filtered using $0.45 \mu \mathrm{m}$ syringe filter before measuring the 121 dissolved organic matter. $\mathrm{UV}_{254}$ absorbance was measured using UV-754 UV/VIS spectrophotometer 122 (Shimadzu, Japan) while the detailed organic matter characterisation was performed using liquid 123 chromatography-organic carbon detection or LC-OCD (DOC-Labor, Germany) as per the procedure 124 described elsewhere [24]. Inorganic elements such as $\mathrm{Al}, \mathrm{Fe}, \mathrm{Cu}, \mathrm{Mn}$ and $\mathrm{Zn}$ were analysed using 125 inductively coupled plasma - mass spectrometry or ICP-MS at the Environmental Analysis 126 Laboratory of the Southern Cross University (Australia).

\subsection{Floc characterisation}

The dynamic floc size was measured online when the coagulation/flocculation was in progress, by connecting the flocculating water to a laser diffraction instrument (Malvern 2000, Malvern, UK). The schematic of the on-line floc measurement system used in this study is presented in Figure 1.

\section{Figure 1}

The strength and recoverability factors of the flocs formed during the coagulation process were determined by subjecting the flocs to initial growth, breakage and regrowth cycle. The initial floc growth phase was carried out at a slow mixing speed of $40 \mathrm{rpm}$ for 15 minutes, then the aggregated flocs were subjected to a high mechanical shear force by rapid mixing at $200 \mathrm{rpm}$ for one minute. After this breakage phase, slow mixing at $40 \mathrm{rpm}$ was then proceeded for 20 minutes to allow regrowth of flocs. The floc strength factor (SF) and recovery factor (RF) were then calculated as follows [7, 25]: 
$140 \quad R F=\frac{d_{3}-d_{2}}{d_{1}-d_{2}} \times 100$

141 where $d_{1}, d_{2}$, and $d_{3}$ are the average aggregate size of the floc at the plateau before applying the shear

142 force, the average aggregate floc size after aggregate breakage, and the average aggregate floc size 143 after regrowth to a new plateau, respectively.

144 High SF values indicate strong floc strength, i.e., the floc does not easily break at increased shear 145 force. Thus, the higher the SF values, the better ability of the flocs to resist shear forces and breakage. 146 Similarly, high RF value indicates the ability of the flocs to regrow after exposure to high shear force. 147 The floc growth rate was calculated by determining the slope of the rapid growth region [26] as 148 follows:

149 Growth rate $=\frac{\Delta_{\text {size }}}{\Delta_{\text {time }}}$

\section{Results and discussion}

3.1 Coagulation performance of $\mathrm{FeCl}_{3}, \mathrm{TiCl}_{4}$ and PTC for the treatment of coal mining wastewater

\subsubsection{Floc zeta potential and removal efficiencies for turbidity, $\mathrm{UV}_{254}$ and DOC}

The coagulation performance of the three coagulants was assessed in terms of turbidity, $\mathrm{UV}_{254}$ and DOC removal efficiency and the results are presented in Table 2. Prior to the test proper, we initially conducted preliminary tests (data not shown) in order to determine the optimum coagulant dose (i.e., coagulant dose at which $95 \%$ turbidity removal is achieved). In this study, the optimal dosages for

$157 \mathrm{FeCl}_{3}, \mathrm{TiCl}_{4}$ and PTC coagulants were determined to be $0.13 \mathrm{mmol} \mathrm{Fe} / \mathrm{L}, 0.40 \mathrm{mmol} \mathrm{Ti} / \mathrm{L}$ and 0.15 mmol Ti/L, respectively. 
160 The results in Table 2 show that both Ti-based coagulants (i.e., $\mathrm{TiCl}_{4}$ and PTC) obtained better

161 performance than $\mathrm{FeCl}_{3}$ coagulant in reducing the turbidity and $\mathrm{UV}_{254}$ of CMWW; however, PTC

162 showed the lowest DOC removal efficiency among the three coagulants.

The difference in DOC removal efficiency between $\mathrm{TiCl}_{4}$ and PTC may be explained by the difference in hydrolysed $\mathrm{Ti}$ species present in the solution. In fact, the dominant hydrolyzates of $\mathrm{TiCl}_{4}$ were most likely $\operatorname{Ti}(\mathrm{OH})^{3+}$ or $\operatorname{Ti}(\mathrm{OH})_{2}{ }^{2+}$ which then formed complex with negatively charged NOM via charge neutralization [27]. For PTC however, the low DOC removal efficiency might be explained by the formation of $\mathrm{Ti}_{\mathrm{n}}(\mathrm{OH})_{\mathrm{m}}^{4 n-m}$ complexes with high $\mathrm{m}$ value, such as $\mathrm{Ti}(\mathrm{OH})_{3}^{+}, \mathrm{Ti}(\mathrm{OH})_{4}^{0}$, or even negative ions $\left(\mathrm{Ti}(\mathrm{OH})_{5}^{-}\right.$and $\mathrm{Ti}(\mathrm{OH})_{6}^{2-}$ ) which led to unfavorable complexation with negatively charged NOM macromolecules resulting in a low DOC removal efficiency [18].

It should be noted though that PTC achieved higher or comparable performance than $\mathrm{TiCl}_{4}$ in terms of turbidity and $\mathrm{UV}_{254}$ removal by employing a much lower dose, which suggests that PTC could be potentially a more cost-effective coagulant than $\mathrm{TiCl}_{4}$. Besides, the effluent $\mathrm{pH}$ after $\mathrm{TiCl}_{4}$ flocculation decreased to 3.43 (Table 2) while the $\mathrm{pH}$ with both $\mathrm{FeCl}_{3}$ and PTC flocculation remained neutral (i.e. in the $\mathrm{pH}$ range 6-8). The difference in effluent $\mathrm{pH}$ between $\mathrm{TiCl}_{4}$ and $\mathrm{PTC}$ shows that the low $\mathrm{pH}$ after flocculation associated with $\mathrm{TiCl}_{4}$ can be managed to a certain degree by developing PTC which minimised the release of hydrogen ions through the prehydrolysis of the Ti-species [18].

To assess the destabilisation potential of the coagulants, we investigated the changes in floc zeta potential, which is also often employed as a tool to evaluate the coagulation mechanism involved, and is usually explained in terms of charge neutralisation and sweep flocculation [28]. Under the optimum coagulant dose conditions, the floc zeta potential after flocculation for $\mathrm{FeCl}_{3}, \mathrm{TiCl}_{4}$ and PTC was -5.3 $\mathrm{mV},-3.7 \mathrm{mV}$ and $-3.2 \mathrm{mV}$ (Table 2), respectively. This suggests that charge neutralisation could play an important role during the flocculation process of all three coagulants as the initial zeta potential of the CMWW was $-30.9 \mathrm{mV}$. In a previous study by Cheng [20], it was mentioned that the possible 
mechanisms involved in the coagulation of humic acid (HA) by $\mathrm{FeCl}_{3}$ was charge neutralisation and bridging adsorption. Additionally, it was found that the fraction removed by bridging adsorption was higher than that removed by charge neutralisation in the $\mathrm{pH}$ range of 7.5-9. In the present study, the initial $\mathrm{pH}$ of the CMWW was about 7.3, which is close to this $\mathrm{pH}$ range and may therefore suggest that, bridging adsorption together with charge neutralisation could be the main coagulation mechanisms using $\mathrm{FeCl}_{3}$ coagulant [29]. With the use of $\mathrm{TiCl}_{4}$, several studies [30-32] have demonstrated that the main coagulation mechanisms was charge neutralisation. While for the PTC coagulant, a recent study by Zhao et al. [18] indicated that charge neutralisation may be the predominant coagulation mechanism as the zeta potential was close to zero after flocculation.

In the present study, complete charge neutralisation was not achieved with all three coagulants and this is evident from the presence of negative surface charges after flocculation. These results therefore indicate that charge neutralisation is not the only mechanism involved during the coagulation/flocculation of the coagulants tested, but other mechanisms such as sweep coagulation and/or bridging adsorption might also have played a role facilitating the floc aggregation.

\subsubsection{Organic matter removal based on LC-OCD characterisation} In order to study further details about the nature of the organic species before and after coagulation/flocculation, LC-OCD characterisation was used and the results are presented both in Figure 2 and Table 3. LC-OCD characterisation results indicate that the CMWW is mainly composed of humic substances and low molecular weight (LMW) neutrals with a small amount of biopolymers and building blocks (i.e. less than 1\%). Table 3 shows the percentage of organic fractions as a function of the total DOC and it can be noted that, CMWW is predominantly composed of hydrophilic compounds accounting to about $87 \%$ of the total DOC.

\section{Figure 2}

As shown in Figure 2, the reduction in the humic substances for the three coagulants was found to be not quite significant after the coagulation process. A new peak appeared at about 70 minutes for PTC, 
which can be attributed to the break-down of the high molecular weight (HMW) humics to LMW

210 humics and building blocks. Table 3 shows that for all three coagulants, the DOC removal was quite 211 low (i.e., less than 25\%), however, considering the composition of the CMWW, this result is not 212 surprising. In fact, it has been already demonstrated before that flocculation preferentially removes the 213 hydrophobic natural organic matter (NOM) fraction [33]. Besides, it has also been demonstrated that coagulation is mostly effective for HMW organics like biopolymers and the CMWW used in this study had very low HMW compounds concentration. $\mathrm{TiCl}_{4}$ was used in a study by Jeong et al. [34] to remove the organic matter in seawater as a pretreatment to reduce membrane fouling. They found that

$217 \mathrm{TiCl}_{4}$ not only completely removed the biopolymers but also showed higher performance (compared to $\mathrm{FeCl}_{3}$ ) for the removal of humics and LMW neutrals. In the present study, however, $\mathrm{FeCl}_{3}$ showed higher performance for the removal of both humic substances and LMW neutrals than the Ti-based coagulants.

Table 3

\subsubsection{Removal of multivalent metals based on ICP-MS analysis}

The CMWW used in this study contains variable concentration of multivalent metals from 0.247 $\mathrm{mg} / \mathrm{L}$ for aluminium to $0.024 \mathrm{mg} / \mathrm{L}$ for zinc. ICP-MS analyses were performed before and after flocculation to determine the removal efficiency of these multivalent metals for all three coagulants and their results are presented in Figure 3.

\section{Figure 3}

Figure 3 shows that the Ti-based coagulants achieved better multivalent metal removal efficiency than $\mathrm{FeCl}_{3}$. For instance, the iron removal efficiency was only $59.1 \%$ with $\mathrm{FeCl}_{3}$, however, $\mathrm{PTC}$ and $\mathrm{TiCl}_{4}$ achieved a removal efficiency of more than $90 \%$. It has to be noted that the lower iron removal efficiency observed for $\mathrm{FeCl}_{3}$ can be biased due to the potential residual iron from the $\mathrm{FeCl}_{3}$ coagulant itself. 
233 One possible mechanism for the removal of multivalent metals by titanium coagulants could be due to

234 the formation of metal-NOM complex [35]. The monomer Ti species (i.e. $\mathrm{Ti}(\mathrm{OH})^{3+}, \mathrm{Ti}(\mathrm{OH})_{2}{ }^{2+}$ or $235 \mathrm{Ti}(\mathrm{OH})_{3}{ }^{+}$might be the dominant hydrolyzates [27]) could firstly adsorb (i.e., physically through 236 charge neutralisation or chemically through chemical bridging adsorption) NOM containing 237 negatively-charged functional groups to form NOM-Ti(OH $)_{x}^{(4-x)}$ complexes, which will then confer 238 the flocs with a negative surface charge. These negatively-charged flocs could then attract and adsorb 239 the positively-charged multivalent metal ions present in the solution to form other complexes such as 240 metal-NOM-Ti $(\mathrm{OH})_{\mathrm{x}}{ }^{(4-\mathrm{x})}$. Another possible removal mechanism could be the precipitation of insoluble 241 metal compounds (i.e., $\mathrm{Al}, \mathrm{Cu}, \mathrm{Fe}, \mathrm{Mn}$ and $\mathrm{Zn}$ ) followed by bridging adsorption onto suspended 242 colloids since all three coagulants demonstrated both high turbidity and multivalent removal 243 efficiencies. It is expected that the formed colloids will become enmeshed in the settling sweep floc 244 and be removed from the suspension [36].

\subsection{Dynamic variation of floc size during flocculation}

246 Floc formation, breakage and regrowth during the coagulation-flocculation process using $\mathrm{FeCl}_{3}, \mathrm{TiCl}_{4}$ 247 and PTC under optimum coagulant dose condition were monitored online using Mastersizer 2000 and 248 the results are displayed in Figure 4.

\section{$249 \quad$ Figure 4}

250 The introduction of slow mixing at $40 \mathrm{rpm}$ resulted to a rapid increase in floc sizes reaching a plateau 251 (i.e., a balance between floc growth rate and floc breakage rate) for all coagulants tested (Figure 4). 252 When the high speed mixing was introduced at $200 \mathrm{rpm}$, the floc size immediately decreased up to $25360 \%$ of the original floc sizes, primarily due to the higher applied shear forces to the flocs resulting to 254 their breakage. Upon the reintroduction of slow mixing, the flocs sizes began to regrow, however, none of the flocs could recover back to their initial floc size before breakage, for all three coagulants. 
Table 4 shows the floc size at the different stages (i.e. before breakage, after breakage, and after

257 regrowth), the floc growth rate and the calculated SF and RF based on equations 1 and 2. It can be seen that all three tested coagulants showed different floc sizes and growth rates. Ti-based coagulants showed a faster floc growth rate with larger floc sizes indicating that both $\mathrm{TiCl}_{4}$ and PTC have the ability to form larger aggregates within a shorter retention time than $\mathrm{FeCl}_{3}$. This is a significant advantage as a shorter retention time coupled with larger floc size will ultimately lead to smaller and more compact flocculation and sedimentation tanks as larger particles generally settled down more rapidly than smaller particles of comparable density [22]. Both the floc growth rate and floc size during the coagulation process varied in the following order: $\mathrm{PTC}>\mathrm{TiCl}_{4}>\mathrm{FeCl}_{3}$ (Table 4). This shows the obvious benefits of using Ti-based coagulants over Fe-based coagulant since the resultant flocs present larger size regardless of floc growth, breakage and regrowth process. Finer flocs are generally more prone to suspend in the supernatant, thus larger flocs will achieve better removal efficiency by settling. This may also explain the lower turbidity removal efficiency of $\mathrm{FeCl}_{3}$ compared to Ti-based coagulants.

Table 4

\section{$271 \quad 3.3 \quad$ Floc breakage and recovery}

272 As summarised in Table 4, Ti-based coagulants showed higher $\mathrm{SF}$ than $\mathrm{FeCl}_{3}$, while $\mathrm{TiCl}_{4}$ obtained the highest RF from all the three coagulants (i.e. $18.3 \%$ against $11.1 \%$ and $10.9 \%$ for $\mathrm{PTC}$ and $\mathrm{FeCl}_{3}$, respectively). Previous studies reported that flocs formed by sweep flocculation have generally weaker RF after breakage than those formed by charge neutralisation [37]. This may indicate that sweep flocculation could be the main mechanism for both $\mathrm{FeCl}_{3}$ and PTC while charge neutralisation might have played a more important role for $\mathrm{TiCl}_{4}$. However, the poor recoverability of all the three tested coagulants (i.e. RF < 20\%) suggests that besides charge neutralisation and sweep flocculation, bridging adsorption of NOM could also be another major removal mechanism involved in the coagulation-flocculation process. In fact, Gregor et al. [38] explained that the main removal route of 
281 HA via coagulation varies depending on the $\mathrm{pH}$ conditions as follows: precipitation by forming

282 insoluble complexes at $\mathrm{pH}<6$, and bridging adsorption of $\mathrm{HA}$ onto hydroxide solid at $\mathrm{pH}>6$.

283 Figure 5 shows the particle size distribution (PSD) of the three tested coagulants before breakage, 284 after breakage and after regrowth. Results indicated that for all the three coagulants, the floc size after 285 breakage was about half the initial floc sizes. After regrowth, there was a slight shift in the peak 286 towards the larger sizes which indicated the floc reformation. The results in Table 4 show that the increase in floc size after breakage was about 10-15\% for all coagulants. Analysis of PSD also clearly indicates the poor recoverability of all three coagulants as the difference in floc size before breakage and after regrowth is significant.

Figure 5

\section{Conclusions}

292 In the present study, the performance of a recently developed PTC coagulant was assessed and compared with $\mathrm{TiCl}_{4}$ and conventional $\mathrm{FeCl}_{3}$ for the treatment of coal mining wastewater. Coagulation performances were evaluated in terms of four different water quality parameters (i.e. turbidity, $\mathrm{UV}_{254}$, DOC and inorganic compounds) and flocs characteristics (i.e. floc size, strength and recoverability). The following conclusions are drawn from this study:

1. Both Ti-based coagulants (PTC and $\mathrm{TiCl}_{4}$ ) showed better efficiency in removing turbidity, $\mathrm{UV}_{254}$ and inorganic compounds from CMWW compared to $\mathrm{FeCl}_{3}$. However, the much smaller coagulant dose of PTC used under optimum conditions, which still resulted to similar or even higher removal efficiency than $\mathrm{TiCl}_{4}$ makes PTC a more cost-effective coagulant.

2. During the initial floc growth period, PTC showed the fastest floc growth rate (i.e. 285.3 $\mu \mathrm{m} / \mathrm{min}$ ) combined with the largest floc size of $899.5 \mu \mathrm{m}$, indicating significant advantages offered by PTC in terms of compact (smaller size) mixing and sedimentation units. 
3. Both PTC and $\mathrm{TiCl}_{4}$ showed higher strength factors than that of $\mathrm{FeCl}_{3}$, however, between the two, PTC had lower recovery factor than $\mathrm{TiCl}_{4}$, suggesting that PTC floc may require more careful handling during the separation process.

4. Charge neutralisation and bridging adsorption were the main mechanisms involved in $\mathrm{TiCl}_{4}$ coagulation while sweep coagulation and bridging adsorption were found to be the main mechanisms for both PTC and $\mathrm{FeCl}_{3}$ coagulations.

\section{$310 \quad$ Acknowledgements}

311 This work was supported by the Australia Research Council Discovery Projects (ARC DP 312 103103129), a grant from the Chinese National Natural Science Foundation (No 51278283), the

313 Shanghai Tongji Gao Tingyao Environmental Science \& Technology Development Foundation 314 (STGEF), and the scholarship from the China Scholarship Council. 
1. Trade at a Glance 2013. 2013 02-02-2015 02-02-2015]; Available from: https://www.dfat.gov.au/trade/resources/trade-at-a-glance/Pages/top-goods-services.aspx.

2. Thiruvenkatachari, R., M. Younes, and S. Shi, Coal mine site investigation of wastewater quality in Australia. Desalination \& Water Treatment, 2011. 32(1-3): p. 357-364.

3. Corbett, R.G., Effects of coal mining on ground and surface water quality, Monongalia County, West Virginia. Science of the Total Environment, 1977. 8(1): p. 21-38.

4. Tripathy, T., N. Karmakar, and R. Singh, Development of novel polymeric flocculant based on grafted sodium alginate for the treatment of coal mine wastewater. Journal of Applied Polymer Science, 2001. 82(2): p. 375-382.

5. Kusin, F., A. Jarvis, and C. Gandy, Hydraulic performance assessment of passive coal mine water treatment systems in the UK. Ecological Engineering, 2012. 49: p. 233-243.

6. Sapsford, D. and I. Watson, A process-orientated design and performance assessment methodology for passive mine water treatment systems. Ecological Engineering, 2011. 37(6): p. 970-975.

7. Jarvis, P., B. Jefferson, and S.A. Parsons, Breakage, regrowth, and fractal nature of natural organic matter flocs. Environmental Science \& Technology, 2005. 39(7): p. 2307-2314.

8. Duan, J. and J. Gregory, Coagulation by hydrolysing metal salts. Advances in Colloid and Interface Science, 2003. 100: p. 475-502.

9. Kane, M., Conventry Area Sewage Sludge Disoposal Scheme: Development of Strategy and Early Operating Experiences. Water and Environment Journal, 1987. 1(3): p. 305-314.

10. Nassar, A.M., M. Smith, and S. Afifi, Palestinian experience with sewage sludge utilizing reed beds. Water and Environment Journal, 2009. 23(1): p. 75-82.

11. Shon, H., et al., Preparation of Titanium Dioxide (TiO2) from Sludge Produced by Titanium Tetrachloride (TiCl4) Flocculation of Wastewater. Environmental science \& technology, 2007. 41(4): p. 1372-1377.

12. Zhao, Y., et al., Floc characteristics of titanium tetrachloride (TiCl4) compared with aluminum and iron salts in humic acid-kaolin synthetic water treatment. Separation and Purification Technology, 2011. 81(3): p. 332-338.

13. Zhao, Y.X., et al., Coagulation characteristics of titanium (Ti) salt coagulant compared with aluminum (Al) and iron (Fe) salts. Journal of Hazardous Materials, 2011. 185(2-3): p. 15361542.

14. Shon, H., et al., Preparation and characterization of titanium dioxide (TiO2) from sludge produced by TiCl4 flocculation with $\mathrm{FeCl3}, \mathrm{Al} 2$ (SO4) 3 and $\mathrm{Ca}(\mathrm{OH}) 2$ coagulant aids in wastewater. Separation Science and Technology, 2009. 44(7): p. 1525-1543.

15. Okour, Y., et al., Preparation and characterisation of titanium dioxide (TiO2) and thioureadoped titanate nanotubes prepared from wastewater flocculated sludge. Bioresource Technology, 2010. 101(5): p. 1453-1458.

16. Hoffmann, M.R., et al., Environmental applications of semiconductor photocatalysis. Chemical Reviews, 1995. 95(1): p. 69-96.

17. Obee, T.N. and R.T. Brown, TiO2 photocatalysis for indoor air applications: effects of humidity and trace contaminant levels on the oxidation rates of formaldehyde, toluene, and 1 , 3-butadiene. Environmental Science \& Technology, 1995. 29(5): p. 1223-1231.

18. Zhao, Y., et al., Preparation and Characterization of Novel Polytitanium Tetrachloride Coagulant for Water Purification. Environmental Science \& Technology, 2013. 47(22): p. 12966-12975.

19. Cao, B., et al., The impact of $\mathrm{pH}$ on floc structure characteristic of polyferric chloride in a low DOC and high alkalinity surface water treatment. Water Research, 2011. 45(18): p. 6181-6188.

20. Cheng, W.P., Comparison of hydrolysis/coagulation behavior of polymeric and monomeric iron coagulants in humic acid solution. Chemosphere, 2002. 47(9): p. 963-969. 
21. Zhan, X., et al., Coagulation behavior of polyferric chloride for removing NOM from surface water with low concentration of organic matter and its effect on chlorine decay model. Separation and Purification Technology, 2010. 75(1): p. 61-68.

22. Boller, M. and S. Blaser, Particles under stress. Water Science and Technology, 1998. 37(10): p. 9-29.

23. McCurdy, K., K. Carlson, and D. Gregory, Floc morphology and cyclic shearing recovery: comparison of alum and polyaluminum chloride coagulants. Water Research, 2004. 38(2): p. 486-494.

24. Huber, S.A., et al., Characterisation of aquatic humic and non-humic matter with sizeexclusion chromatography-organic carbon detection-organic nitrogen detection (LC-OCDOND). Water Research, 2011. 45(2): p. 879-885.

25. Yukselen, M.A. and J. Gregory, Breakage and re-formation of alum flocs. Environmental Engineering Science, 2002. 19(4): p. 229-236.

26. Xiao, F., et al., Comparative study of the effects of experimental variables on growth rates of aluminum and iron hydroxide flocs during coagulation and their structural characteristics. Desalination, 2010. 250(3): p. 902-907.

27. Xu, J., P. Gong, and X. Qin, Research on hydrolysis of TiCl 4 characteristic. Petrochem. Ind. Appl, 2009. 28(6): p. 13-15.

28. Gregory, J. and J. Duan, Hydrolyzing metal salts as coagulants. Pure and Applied Chemistry, 2001. 73(12): p. 2017-2026.

29. Jeong, S., et al., Experimental investigation and modeling of dissolved organic carbon removal by coagulation from seawater. Chemosphere, 2014. 95: p. 310-316.

30. Zhao, Y., et al., Comparison of coagulation behavior and floc characteristics of titanium tetrachloride (TiCl4) and polyaluminum chloride (PACl) with surface water treatment. Chemical Engineering Journal, 2011. 166(2): p. 544-550.

31. Zhao, Y., et al., Comparative study of floc characteristics with titanium tetrachloride against conventional coagulants: Effect of coagulant dose, solution $\mathrm{pH}$, shear force and break-up period. Chemical Engineering Journal, 2013. 233: p. 70-79.

32. Zhao, Y., et al., Coagulation and sludge recovery using titanium tetrachloride as coagulant for real water treatment: A comparison against traditional aluminum and iron salts. Separation and Purification Technology, 2014. 130: p. 19-27.

33. Lee, S., W.S. Ang, and M. Elimelech, Fouling of reverse osmosis membranes by hydrophilic organic matter: implications for water reuse. Desalination, 2006. 187(1): p. 313-321.

34. Jeong, S., et al., Ti-salt flocculation for dissolved organic matter removal in seawater. Desalination and Water Treatment, 2013. 51(16-18): p. 3591-3596.

35. Hankins, N.P., N. Lu, and N. Hilal, Enhanced removal of heavy metal ions bound to humic acid by polyelectrolyte flocculation. Separation and Purification Technology, 2006. 51(1): p. 48-56.

36. Sholkovitz, E. and D. Copland, The coagulation, solubility and adsorption properties of $\mathrm{Fe}$, $\mathrm{Mn}, \mathrm{Cu}, \mathrm{Ni}, \mathrm{Cd}$, Co and humic acids in a river water. Geochimica et Cosmochimica Acta, 1981. 45(2): p. 181-189.

37. Aguilar, M., et al., Microscopic observation of particle reduction in slaughterhouse wastewater by coagulation-flocculation using ferric sulphate as coagulant and different coagulant aids. Water Research, 2003. 37(9): p. 2233-2241.

38. Gregor, J., C. Nokes, and E. Fenton, Optimising natural organic matter removal from low turbidity waters by controlled $\mathrm{pH}$ adjustment of aluminium coagulation. Water Research, 1997. 31(12): p. 2949-2958. 